\title{
Chronopharmacology of the New Uricosuric Diuretic S-8666 in Rats
}

\author{
Akio Fujimura, Kyo-ichi Ohashi and Akio Ebihara \\ Department of Clinical Pharmacology, Jichi Medical School, \\ Minamikawachi-machi, Kawachi-gun, Tochigi 329-04, Japan \\ Received December 13, 1990 Accepted March 16, 1991
}

\begin{abstract}
A new loop diuretic with uricosuric activity, 6,7-dichloro-5-(N,Ndimethylsulfamoyl)-2,3-dihydro-2-benzofuran carboxylic acid (S-8666), was given orally at 12:00 a.m. or 12:00 p.m. in rats. The diuretic of S-8666 and the urinary excretions of the drug and its active metabolite S-8680 (N-demethyl S-8666) were greater at 12:00 a.m. than at 12:00 p.m.. Thus, the present study indicates that the diuretic effects of S-8666 varies with its administration time. Time-dependent variations in the amount of urinary excretions of S-8666 and S- 8680 might be involved in the mechanisms for this phenomenon.
\end{abstract}

6,7-Dichloro-5-(N,N-dimethylsulfamoyl)-2,3dihydro-2-benzofuran carboxylic acid (S-8666) is a new uricosuric diuretic agent with two enantiomers. The $(+)$-enantiomer has predominantly uricosuric activity, while the (-)enantiomer shows diuretic activity $(1,2)$. Each enantiomer has an active metabolite. The demethylated metabolite of S-8666- $(+)$, S-8680$(+)$ has uricosuric activity, and that of S-8666$(-)$, S-8680-(-), has diuretic activity $(1,3)$. The major site of the diuretic action of S-8666 is the cortical thick ascending limb of Henle's loop (CAL) (4) which is common to that of furosemide, a widely used loop diuretic agent.

There is increasing evidence demonstrating time-dependent changes in the effectiveness and toxicity of cardiovascular agents. We already examined chronopharmacological profiles of furosemide in rats. These studies demonstrated that the effects of furosemide arc greater when it is administered during the rats' sleep period than when it is administered during their awake period $(5,6)$. This timedependent change in the diuretic effects of furosemide depends on the time-dependent variations in the urinary amount of furosemide $(5,6)$. Since, similar to furosemide (7), S-8666 is excreted in the urine by active tubular secretion, and subsequently inhibits chloride ion transport in the CAL $(2,4)$, it is assumed that the diuretic effects of the agent also vary with its time of dosing. The present study was therefore undertaken to extend our original observations to another loop diuretic agent. S8666 was given orally at $12: 00 \mathrm{a} . \mathrm{m}$. or $12: 00$ p.m. to rats. The diuretic effects following the agent at 12:00 a.m. were compared to those given at 12:00 p.m. The urinary excretions of S-8666 and its active metabolite S- 8680 were also determined.

Male Wistar rats (Charles River Laboratory, Kanagawa, Japan) $(10-11$ weeks old, $300-$ $350 \mathrm{~g}$ ) were maintaned for more than 2 weeks under conditions of light from 7:00 a.m. to 7:00 p.m. and dark from 7:00 p.m. to 7:00 a.m. with free access to food and water. Four percent body weight (b.w.) of $1 \% \mathrm{NaCl}$ solution was given by gavage into the stomach at 
12:00 a.m. (or 12:00 p.m.) on day 1. Thirty and ninety $\mathrm{mg} / \mathrm{kg} \mathrm{b}$.w. of S-8666 (Shionogi \& Co., Ltd., Osaka, Japan) in $4 \%$ b.w. of $1 \%$ $\mathrm{NaCl}$ was given orally at 12:00 a.m. (or 12:00 p.m.) on day 4 and day 7 , respectively. Urine was collected for 8 hours following vehicle alone or the drug administration at 12:00 a.m. (or 12:00 p.m.). Food and water were deprived for 8 hours after each administration. The administration of the drug was randomly assigned to $12: 00 \mathrm{a} . \mathrm{m}$. or 12:00 p.m. The washout period between the two sets of experiments was 7 days.

A loop diuretic agent inhibits the Na-K-2Cl cotransport system in the CAL. Potassium and chloride are secreted at the distal tubule $(8$, 9). In addition, potassium is reabsorbed at the medullary collecting duct, and it is subsequently secreted at the medullary thick ascending limb of Henle's loop (10). These observations indicate that the urinary amounts of potassium and chloride are not appropriate parameters for estimating the diuretic activity of a loop diuretic agent. Therefore urinary sodium was measured to evaluate the diuretic effect of S-8666 in the present study. Urinary sodium concentration was determined by flame photometry (Flame Photometer 775-A, Hitachi, Tokyo, Japan). Urinary concentrations of S-8666- $(+)$ and S-8666- $(-)$ and their active demethylated metabolites, $S-8680-(+)$ and $\mathrm{S}-8680-(-)$, were measured by Shionogi \& Co., Ltd., using high pressure liquid chromatography (1). The sensitivity of this assay was $0.2 \mu \mathrm{g} / \mathrm{ml}$ and the coefficient of variation was $3.0 \%$. The results are expressed as the means \pm S.E. Data were analyzed by analysis of variance and the Wholly-Significant-Difference Method.

When $4 \%$ b.w. of $\mathrm{NaCl}$ solution was given as an $\mathrm{S}-8666$ control, no significant difference was observed in urine volume or urinary excretion of sodium in the collection period following the 12:00 a.m. administration compared to the collection period beginning at 12:00 p.m. (Fig. 1). Urine volume and urinary sodium excretion increased dose-dependently after S-8666 in the day and night trials. These parameters following 30 and $90 \mathrm{mg} / \mathrm{kg}$ b.w. of the agent were significantly greater at 12:00 a.m. than at $12: 00 \mathrm{p} . \mathrm{m}$. Urinary excretion of S-8666 was significantly greater in the day trial than in the night trial (Table 1). Urinary excretion of its active metabolite $S-8680$ also had a tendency to be greater at 12:00 a.m. than at 12:00 p.m. Urinary excretion of $\mathrm{S}-8666-(+)$ was smaller than that of $S-8666-(-)$, while the value of $S-8680-(+)$ was greater than that of S-8680-(-) in the present study.

The present study demonstrates that S-8666 produces an increased sodium and water diuresis when administered at 12:00 a.m. corresponding to the rats' sleep period compared to that administered at $12: 00 \mathrm{p} . \mathrm{m}$., which is their awake period. This finding is similar to the chronopharmacological profiles of furosemide in rats $(5,6)$. The present study

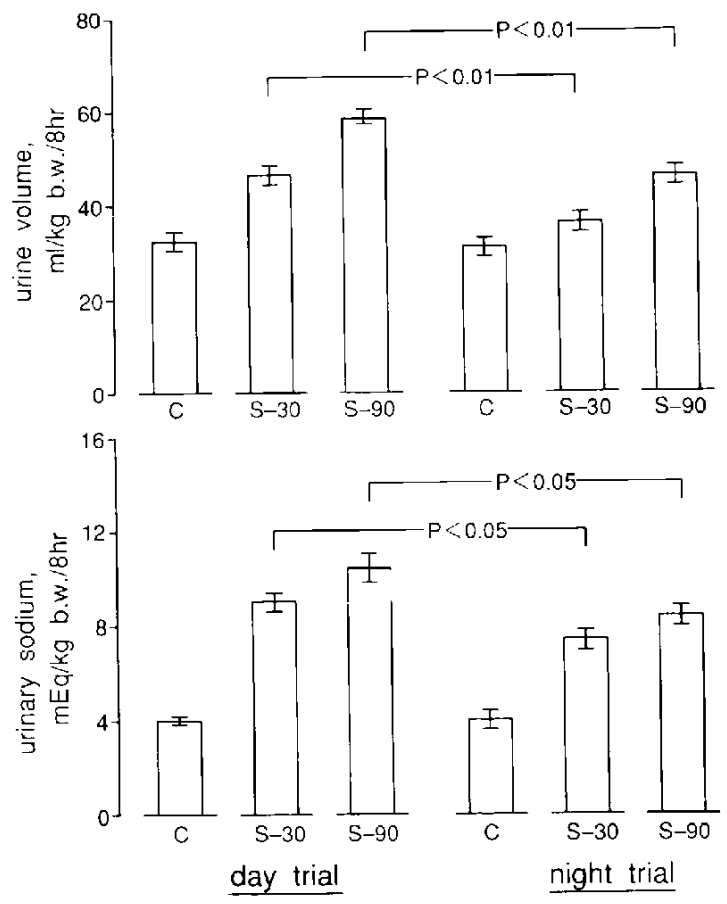

Fig. 1. Urine volume and urinary sodium excretion following oral administration of $\mathrm{S}-8666$ at 12:00 a.m. (day trial) or 12:00 p.m. (night trial) in rats. Mean \pm S.E., $\mathbf{n}=16$. Urine was collected for 8 hours after $4 \%$ body weight (b.w.) of $1 \% \mathrm{NaCl}$ solution (C) or $\mathrm{S}-8666$ [30 $\mathrm{mg}(\mathrm{S}-30)$ or $90 \mathrm{mg}$ (S-90)/ $\mathrm{kg} \mathrm{b.w.]} \mathrm{in} 4 \%$ b.w. of $1 \% \mathrm{NaCl}$. 
Table 1. Urinary excretions of enantiomers of S-8666 (S-8666- $(+)$ and S-8666$(-)$ ) and their active demethylated metabolites (S-8680- $(+)$ and S-8680-( -$)$ ) following oral administration of the agent at 12:00 a.m. (day trial) or at 12:00 p.m. (night trial) in rats

\begin{tabular}{|c|c|c|c|c|}
\hline \multirow{2}{*}{ Parameter } & \multicolumn{2}{|c|}{ Day trial } & \multicolumn{2}{|c|}{ Night trial } \\
\hline & $S-30$ & $S-90$ & $S-30$ & $S-90$ \\
\hline $\begin{array}{l}\mathrm{S}-8666-(+), \\
\mu \mathrm{g} / \mathrm{kg} \mathrm{b} . \mathrm{w} . / 8 \mathrm{hr} \\
\mathrm{S}-8680-(+), \\
\mu \mathrm{g} / \mathrm{kg} \mathrm{b.w.} / 8 \mathrm{hr}\end{array}$ & $\begin{array}{l}984 \pm 100^{*} \\
2704 \pm 178\end{array}$ & $\begin{array}{l}3206 \pm 351^{* *} \\
7783 \pm 599^{* *}\end{array}$ & $\begin{array}{r}719 \pm 67 \\
2666 \pm 287\end{array}$ & $1990 \pm 297$ \\
\hline $\begin{array}{l}\mathrm{S}-8666-(-) \\
\mu \mathrm{g} / \mathrm{kg} \mathrm{b.w.} / 8 \mathrm{hr} \\
\mathrm{S}-8680-(-) \\
\mu \mathrm{g} / \mathrm{kg} \mathrm{b.w.} / 8 \mathrm{hr}\end{array}$ & $1629 \pm 118^{*}$ & $\begin{array}{l}5343 \pm 472^{* *} \\
2349 \pm 223^{*}\end{array}$ & $\begin{array}{l}1177 \pm \\
703 \pm\end{array}$ & $\begin{array}{l}3734 \pm 604 \\
1907 \pm 300\end{array}$ \\
\hline
\end{tabular}

Mean \pm S.E., $n=16$. Urine was collected for 8 hours after $S-8666[30 \mathrm{mg}$ (S-30) or $90 \mathrm{mg}(\mathrm{S}-90) / \mathrm{kg}$ b.w.|. ${ }^{*}=\mathrm{P}<0.10,{ }^{*}=\mathrm{P}<0.05,{ }^{* *}=\mathrm{P}<0.01$, compared to the night trial

also shows that the urinary excretions of $\mathrm{S}$ 8666-(-) and its active metabolite S-8680-(-) are greater in the day trial than in the night trial. Since the main site of action of S-8666 is the luminal side of the thick ascending limb of Henle's loop (4), these time-dependent changes in the diuretic effects of S-8666 might, at least in part, depend on the time-dependent variations in the urinary amount of S-8666$(-)$ and S-8680-(-). These daily variations in the urinary amount of the agent might be accounted for by either or both of the following mechanisms: 1) faster absorption rate after S-8666 at 12:00 a.m. compared to that at 12:00 p.m. Temporal variations of absorption rate have already been documented for several drugs $(11) ; 2$ ) higher excretion rate in the day trial compared to that in the night trial. This mechanism has been demonstrated by an intra-vascular injection study using furosemide $(5,6)$. Although a circadian variation is demonstrated in renal glomerular function (12, 13), a rhythmicity in renal tubular function has not been demonstrated. Since S-8666 and furosemide are secreted by renal tubules, a circadian variation might also exist in tubular secretory function.

Rats metabolize uric acid to allantoin in the liver with uricase (14). Therefore, when prop- erties of uricosuric agents are evaluated using rats, the animals must be treated with the uricase inhibitor oxonate (15). Since the possibility that oxonate alters the chronopharmacological profiles of S-8666 can not be ruled out, the rats were not treated with oxonate in the present study. Urinary excretions of S-8666$(+)$ and $\mathrm{S}-8680-(+)$, which have predominantly uricosuric activities, are greater when the agent is given at 12:00 a.m. than when it is administered at $12: 00 \mathrm{p.m}$. Although the amount of urinary uric acid was not determined, these data indicate that the uricosuric activity of S-8666 is also greater in the day trial than that in the night trial.

Urinary excretion of S-8666-(+) was smaller than that of $S-8666-(-)$, while the excretion of the metabolite of $\mathrm{S}-8666-(+)$ was greater than that of the metabolite of S-8666- $(-)$. Since the renal clearance of S-8666- $(+)$ and S8666-(-) did not differ (2), the metabolic clearance of S-8666- $(+)$ might be greater than that of S-8666- $(-)$. Further studies are needed to evaluate this hypothesis.

In summary, the present study demonstrated the time-dependent variations in the diuretic effects of S-8666 and the urinary excretion of S-8666- $(-)$ and S-8680-(-). Since the amount of urinary S-8666- $(+)$ and S-8680- 
$(+)$, which exert predominantly uricosuric action, varied with the administration time, the uricosuric activity of S-8666 might also be influenced by its time of dosing.

\section{Acknowledgements}

We thank Akio Matsuura, Ph.D. of Shionogi \& Co., Ltd. for measuring urinary concentration of S-8666 and S-8680.

\section{REFERENCES}

1 Yonetani, Y., Iwaki, K., Shinosaki, T., KawaseHanafusa, A., Harada, H. and van Es, A.A.: A new uricosuric diuretic, $S-8666$, in rats and chimpanzees. Japan. J. Pharmacol. 43, $389-398$ (1987)

2 Nakamura, M., Kawabata, T., Itoh, T., Miyata, K. and Harada, H.: Stereoselective saluretic effect and localization of renal tubular secretion of enantiomers of S-8666, a novel uricosuric antihypertensive diuretic. Drug Dev. Res. 19, 23-36 (1990)

3 Harada, H. and Yonetani, Y.: 5-Sulfamoyl-2,3dihydrobenzofuan-2-carboxylic acid derivatives: S-8666, a favorable candidate with uricosuric and diuretic activities. Drugs of the Future 13, 257264 (1988)

4 Shimizu, T., Nakamura, M. and Imai, M.: Renal action of a novel uricosuric diuretic, S-8666. II. Effects on $\mathrm{Cl}^{-}$and urate transport in isolated perfused rabbit renal tubules. J. Pharmacol. Exp. Ther. 245, 651-657 (1988)

5 Fujimura, A. and Ebihara, A.: Chronopharmacological study of furosemide in rats. Life Sci. 38, $1215-1220$ (1986)

6 Fujimura, A. and Ebihara, A.: Chronopharmacological study of furosemide in rats: (II) Influence of $\beta$-adrenoceptor blockade. Life Sci. 42, $1431-$ 1437 (1988)

7 Weiner, I.M. and Mudge, G.H.: Diuretics and other agents employed in the mobilization of edema fluid. In The Pharmacological Basis of Thera- peutics, 7th edition, Edited by Gilman, A.F., Goodman, L.S., Rall, T.W. and Murad, F., p. 887-907, MacMillan Publishing Company, New York (1985)

8 Ellison, D.H., Velázquez, H. and Wright, F.S.: Stimulation of distal potassium secretion by low lumen chloride in the presence of barium. Am. J. Physiol, 248, F638-F649 (1985)

9 Ellison, D.H., Velázquez, H. and Wright, H.S.: Unidirectional potassium fluxes in renal distal tubule: effects of chloride and barium. Am. J. Physiol. 250, F885-F894 (1986)

10 Stokes, J.B.: Consequences of potassium recycling in the renal medulla. J. Clin. Invest. 70, 219-229 (1982)

11 Bruguerolle, B.: Temporal aspects of drug absorption and drug distribution. In Chronopharmacology, Edited by Lemmer, B., p. 3-13, Marcel Dekker, Inc., New York (1989)

12 Luke, D.R., Wasan, K.M. and Vadiei, K.: Lack of circadian variation in renal function in the obese rat: influence of continuous food and water intake. In Chronobiology: Its Role in Clinical Medicine, General Biology, and Agriculture, Part A, Edited by Hayes, D.K., Pauly, J.E. and Reiter, R.J., p. 131 -136, Wiley-Liss Inc. (1990)

13 Koopman, M.G., Koomen, G.C.M., Krediet, R.T., de Moor, E.A.M., Hoek, F.J. and Arisz, L.: Circadian rhythm of glomerular filtration rate in normal individuals. Clin. Sci. 77, 105-111 (1989)

14 Roch-Ramel, F. and Peters, G.: Urinary excretion of uric acid in nonhuman mammalian species. In Handbook of Experimental Pharmacology, Vol. 51, Uric Acid, Edited by Kelley, W.N. and Weiner, I.M., p. 211-255, Springer-Verlag, Berlin, Heidelberg and New York (1978)

15 Yonetani, Y. and Iwaki, K.: Effects of uricosuric drugs and diuretics on uric acid excretion in oxonate-treated rats. Japan. J. Pharmacol. 33, $947-954(1983)$ 